\title{
Students' perception of the level of traffic safety provided in school areas
}

\author{
S. Basbas ${ }^{1} \&$ A. Kokkalis ${ }^{2}$ \\ ${ }^{1}$ Aristotle University of Thessaloniki, Greece \\ ${ }^{2}$ Democritus University of Thrace, Greece
}

\begin{abstract}
The need to provide a safe environment for vulnerable road users in the road network is essential when considering the land-use system and the transportation system in an area. This need is more important in the case of students due to the fact that they are not always in the position to easily realize the danger of the road traffic and thus take the necessary precautionary measures. In the framework of this paper the results of a research concerning high school students' perception of the level of traffic safety provided in school areas are presented. Students in high schools (first to third grade) participated in a questionnaire-based survey in the Municipalities of Kalamaria and Larissa, Greece. The perception of the traffic safety level in the vicinity of schools, the reasons for which students feel unsafe, their knowledge of the Highway Code, their participation in traffic education events, their opinion about the traffic calming measures and the transport modes used for the trips to and from schools are examined and presented in this paper.
\end{abstract}

Keywords: traffic safety, safety behaviour, perceptions, high school students.

\section{Introduction}

Traffic accidents are an important problem in most countries all over the world. An estimated 1.17 million deaths occur each year worldwide due to road accidents, where $65 \%$ of deaths involve pedestrians and $35 \%$ of pedestrian deaths are children. The need to provide a safe environment for the vulnerable road users in the road network is essential when considering the land-use system and the transportation system in an area. This need is more important in the case of students due to the fact that they are not always in the position to easily realize 
the danger of the road traffic and take the necessary precaution measures. Therefore, it is important to design and implement the appropriate safety measures in school areas and also to evaluate their effectiveness. Child traffic fatalities are affected by various factors. The results of survey concerning the relationship between quality of life and child traffic fatalities [1] show that "with the exception of the bicycle fatalities, traffic fatalities among children tend to decline with increasing quality of life". The transport mode used by students is an important factor which affects their safety. The following results were obtained in a study carried out in Melbourne, Australia [2], as far as the proportion of children walking or cycling to school is concerned: $44 \%$ for boys $5-6$ years old, $48.2 \%$ for girls of the same age, $65.1 \%$ for boys $10-12$ years old, $56.8 \%$ for girls of the same age. It should be mentioned at this point that walking and cycling at the two main modes of transport for children's independent mobility and they are also very important for environmental reasons [3]. It is also important to notice that differences in levels of independent mobility were observed between schools in Canberra, England and Germany due to various reasons (i.e., dominance of the motor vehicle in the development of a lowdensity city) [3]. A number of 1760 middle school (sixth, seventh and eighth standard) boys aged between 10 and 16 were included in a study in Yamunanagar, India, concerning the use of motorcycle [4]. It was found that $15 \%$ of the students had an accident as they were riding a motorcycle while aggressive behaviour and previous encounter with the police are the two strong predictors of the accidents. According to a study of 1557 students in grades 6-8 across 14 schools in the Kathmandou and Lalitpur districts of Nepal, 23\% of adolescents reported pedestrian injuries [5]. These adolescents were commonly injured by motorcycles and motor vehicles while crossing the road. They were also commonly injured by bicycles and motorcycles while walking and playing. Various traffic calming measures have been implemented in the vicinity of schools worldwide. An evaluation study was carried out in 4 sites (where schools were situated nearby) in Boras, Sweden [6] concerning the short-term effects of countermeasures for improved safety and mobility at marked pedestrian crosswalks. At the Trandared sites (change of code but no reconstruction), 57\% of the school children stated that the safety had improved while at other sites (change of code and reconstruction) the respective percentage was higher $(83 \%$ in average). Results from sites close to schools at Malmo, Trolhattan and Boras together with analyses of Finnish and Swedish police reports [7] have shown that the safety of children and elderly has further been improved at sites where visibility, orientation and clarity are sufficient. Preadolescent school-age children did not consistently make safe crossing decisions especially when the approach speeds of vehicles exceed $55 \mathrm{kph}$ [8]. Educational programmes also play an important role in road safety although several studies have concluded that "it is important to distinguish children's knowledge of appropriate behaviour from their actual behaviour. Often the two are little, if at all, related" [9]. The British Institute of Traffic Education Research carried out a research concerning the attitudes, knowledge and intended behaviour of 947 teenage students at three schools, before, immediately after and 3 months after a presentation by a Driving 
Standard Agency (DSA) instructor [10]. At 3 months, mean scores for some statements have changed in favour of safer driving, but there is no reliable evidence that this conclusion is of general applicability. According to the Child Pedestrian Injury Prevention Project in Australia [11], there is an indication that the educational interventions decelerated the natural increase in children's pedestrian-related risk behaviour. Road crossing skills of young children can be considerably improved both by systematic training in traffic and by cognitive instructions in the classroom provided that the content and methods fulfill certain criteria [12]. It must be also mentioned that, as it was found in a study carried out in Sydney, Australia [13], cultural differences in risk perception should be taken into consideration in the design of safety education programs for childhood pedestrians. Another way to deal with the problem of safety in school areas is the "walking school bus" (WSB) which involves volunteers guiding children to and from school in an orderly manner following established walking routes [14]. This idea has been rapidly adopted within metropolitan Auckland, New Zealand. Voluntary traffic safety clubs is also a tool for the confrontation of traffic safety among children. According to a questionnaire based survey in Sweden [15] addressed to children (member and nonmembers of a traffic safety club), it was found that members do not have a lower accident risk than nonmembers (approximately $20 \%$ of Swedish children are members of the club). In the framework of the present paper the results of a research concerning high school students' perception of the level of traffic safety provided in school areas are presented. Students in high schools (first to third grade) participated in a questionnaire-based survey in the Municipalities of Kalamaria and Larissa, Greece. The perception of traffic safety level in the vicinity of schools, the reasons for which students feel unsafe, their knowledge of the Highway Code, their participation in traffic education events etc. are examined and presented in the paper.

\section{Design of the surveys in Kalamaria and Larissa}

The questionnaire based surveys concerning the perception of the level of traffic safety by the students aged 12-14 (first grade to third grade high school students) took place in the Municipality of Kalamaria, Thessaloniki Greater Area and in the Municipality of Larissa. Both surveys were carried out in the framework of the research activities of the Department of Transportation and Hydraulic Engineering, Faculty of Rural and Surveying Engineering, Aristotle University of Thessaloniki (AUTh) $[16,17]$. The first survey was carried out during the period 2002-03 and the second one during the period 2005-06. In the first case (Kalamaria case study) a number of 348 valid questionnaires were collected and analysed while the respective number for the city of Larissa is 63 . It must be mentioned at this point that the surveys which took place in the high schools selected (one in Larissa and two in Kalamaria) were based on a two-page questionnaire, specially designed for this purpose. Apart from the questionnairebased survey, the traffic calming measures in the vicinity of the schools were examined and vehicle speed measurements were also carried out. 


\section{Analysis of results}

\subsection{Results from the Municipality of Kalamaria case study}

One of the basic findings of the research concerns the perception of the level of traffic safety by the high school students on their way to and from school. The answers by the high school students in Kalamaria have shown that a notable percentage of $23 \%$ of these students feel very unsafe or unsafe while only $30 \%$ of the students feel safe on their trip to and from school. It is also important to investigate the reasons for which these students feel very unsafe or unsafe. These results are presented in Figure 1. High speed of vehicles, high traffic volumes, inadequate sidewalks, absence of pedestrian crossings and limited visual field due to parking are the basic reasons as they have been stated by the students. Speed measurements during the morning peak show that $4.76 \%$ of the vehicles had a speed between 20 and $29 \mathrm{~km} / \mathrm{h}, 42.86 \%$ between 30 and $39 \mathrm{~km} / \mathrm{h}, 43.65 \%$ between 40 and $49 \mathrm{~km} / \mathrm{h}$ and $8.73 \%$ above $50 \mathrm{~km} / \mathrm{h}$ (which is the speed limit in urban areas unless otherwise stated).

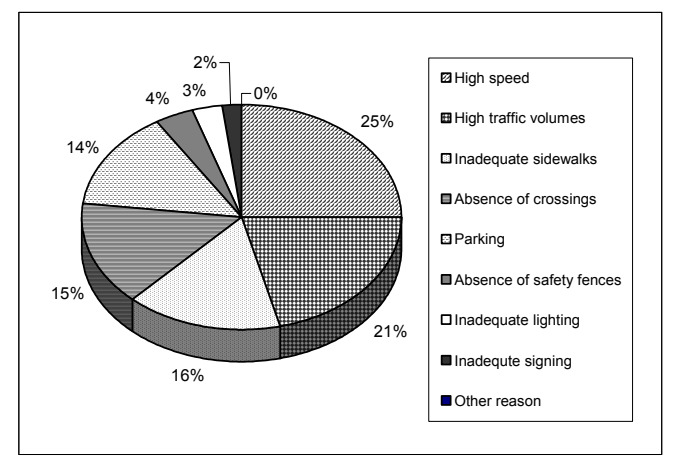

Figure 1: Reasons for the "unsafe" and "very unsafe" answers.

An important aspect of the research concerns the level of knowledge of the Highway Code by the students. It is considered essential for the students to be familiar with the traffic regulations because this enhances the safe use of the road environment. Figure 2 presents the answers in Kalamaria concerning the knowledge of the $\mathrm{HC}(20 \%$ of the students stated that they know nothing about the HC). Only a small \% of the students had the experience of participation to a traffic education event. Such events are often organized in schools with the assistance of the police. Figure 3 presents the answers obtained in Kalamaria. A low percentage $(28 \%)$ stated that they had participated in such events. Therefore it arises that the knowledge of the $\mathrm{HC}$ is not exclusively based on traffic education events but students have other sources of information as well. The perception of traffic safety level is different between students who participated to such events and the rest of the students. The respective results (Figure 4) show 
that students who have participated in such events feel safer (i.e., $26 \%$ of the students with no such experience stated that they feel very unsafe or unsafe compared to $13 \%$ of experienced students).

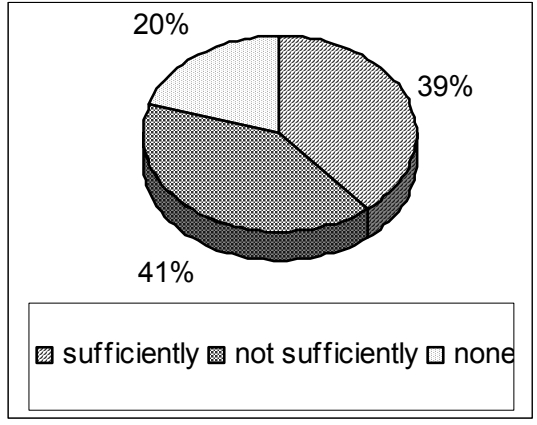

Figure 2: Level of HC knowledge in Kalamaria.

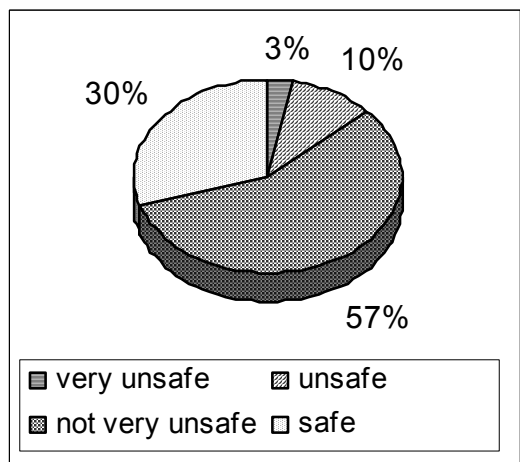

Participated

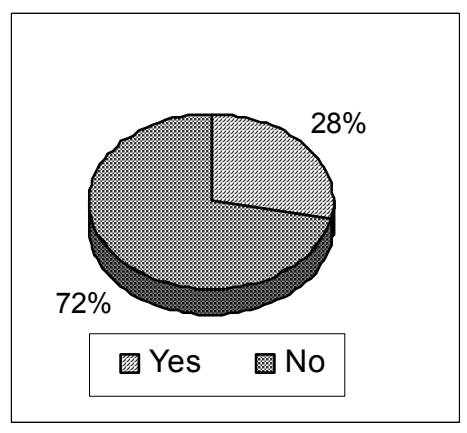

Figure 3: Participation to traffic education events in Kalamaria.

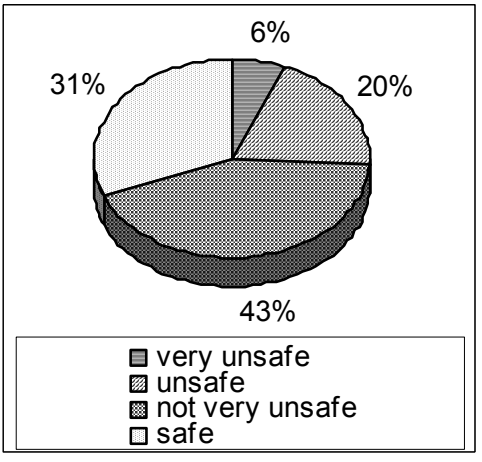

Not participated

Figure 4: Perception of traffic safety level by high school students in Kalamaria related to their participation to a traffic education event.

Various traffic calming measures are often implemented in school areas. These measures include speed humps, raised crosswalks, intersection islands, roundabouts, road narrowing, chicanes, chokers etc. It is interesting to notice (see Figure 5) that the vast majority of the students believe that these measures are at least "enough sufficient" while only $16 \%$ of them believe that these measures are insufficient. At the same time it should also be noticed that the percentage of students who feel unsafe or unsafe $(23 \%)$ is higher than the percentage $(16 \%)$ of students who believe that the traffic calming measures implemented in the schools areas are insufficient. Therefore it seems that traffic 
calming measures play an important role in students' perception of traffic safety level bur there is still a relatively small part of the students who feel unsafe despite the existence of these measures.

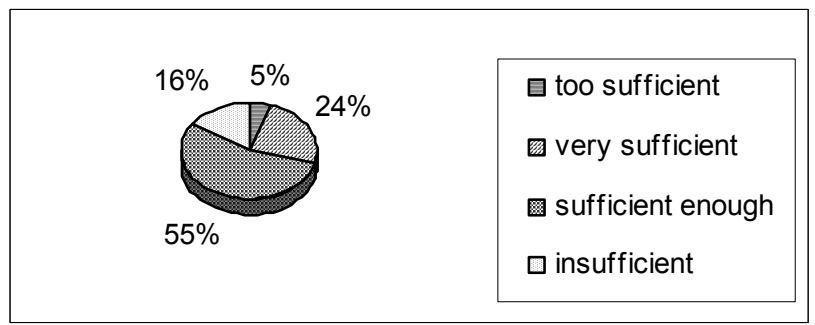

Figure 5: Opinion of the high school students in Kalamaria for the traffic calming measures in their school areas.

It is also interesting to look at the transport mode used by the students on their way to and from schools. These results are presented in Figure 6 and show that that the vast majority (94\%) of students walk (either alone or together with schoolmates) to and from school. A very small percentage (3\%) travels as private car passengers. The use of Public Transport buses is $1 \%$, the use of bicycles is $1 \%$ and the use of motorbikes is also $1 \%$.

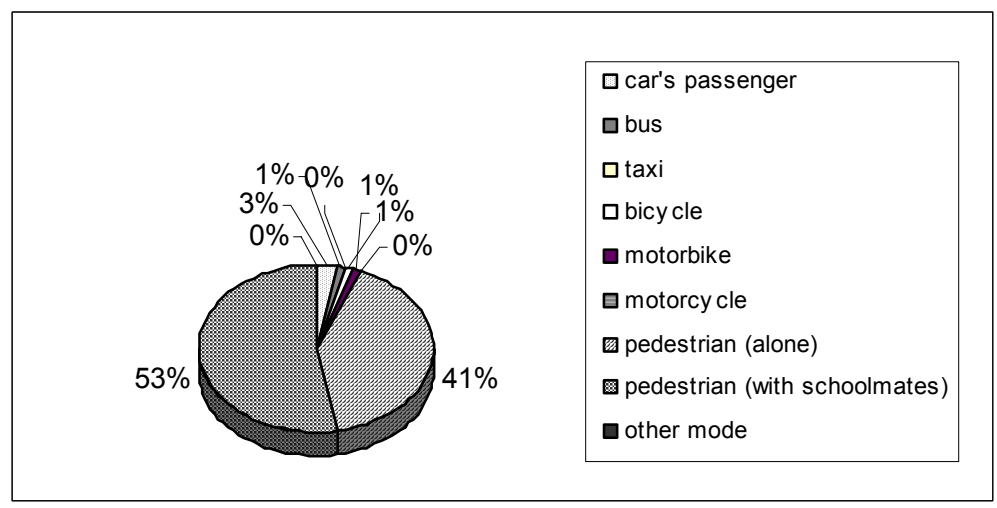

Figure 6: Transport mode used to and from school in Kalamaria.

\subsection{Results from the Municipality of Larissa case study}

The results concerning the perception of the level of traffic safety by high school students on their way to and from school in Larissa show that a notable percentage of $22 \%$ of the students feel very unsafe or unsafe while only $24 \%$ of the students feel safe on their trip to and from school. The percentage of high 
school students who feel unsafe or very unsafe in Larissa is similar to the respective one in Kalamaria (23\%). The investigation of the reasons for which these students feel very unsafe or unsafe are presented in Figure 7. High speed of vehicles, high traffic volumes, absence of pedestrian crossings and limited visual field due to parking are the basic reasons as stated by the students. The effect of high traffic volumes seem to be much more important in Larissa (37\%) than in Kalamaria (21\%). Speed measurements during the morning peak have shown that $82 \%$ of the vehicles had a speed between 20 and $29 \mathrm{~km} / \mathrm{h}, 17.4 \%$ between 30 and $39 \mathrm{~km} / \mathrm{h}$ and only $0.6 \%$ between 40 and $49 \mathrm{~km} / \mathrm{h}$. These results have shown that drivers in Larissa drive at significantly lower speed than drivers in Kalamaria as far as the study areas are concerned. This can be possible explained by the type of the traffic calming measures implemented in the vicinity of schools. Figure 8 presents the answers by the high school students in Larissa concerning their knowledge about the HC. As shown in this Figure, 21\% of the students stated that they knew nothing about the HC. It is very interesting to notice that the results are almost the same as in Kalamaria. Figure 9 presents the answers obtained by the students in Larissa as far as their participation in a traffic education event is concerned. A remarkable low percentage (34\%) stated that they had participated in such events. However this $\%$ is higher than the respective one in Kalamaria (28\%). The perception of traffic safety level for students who participated in traffic education events and for the rest of the students is presented in Figure 10. Results have shown that students who don't have the experience of a traffic education event feel safer compared to the rest of their schoolmates (i.e., 19\% of the students with no such experience stated that they felt very unsafe or unsafe compared to $29 \%$ of experienced students). These results are in the opposite direction compared to the results obtained from Kalamaria. The vast majority of the students believe (see Figure 11) that traffic calming measures in the vicinity of their school are at least "enough sufficient" while $27 \%$ of them believe that these measures are insufficient (this \% is higher than the respective one in Kalamaria, 16\%). It should also be noticed that the percentage of students who feel unsafe or unsafe $(22 \%)$ is lower than the percentage $(27 \%)$ of students who believe that the traffic calming measures implemented in the schools areas are insufficient. Therefore it seems that traffic calming measures play an important role in students' perception of traffic safety level in Larissa. The results presented in Figure 12 concern the transport mode used by the students on their way to and from schools. These results have shown that the majority (75\%) of students walk (either alone or together with schoolmates) to and from school but this $\%$ is significantly lower than the respective one in Kalamaria (94\%). It is also important to notice that $6 \%$ of the students travel as private car passengers (compared to $3 \%$ in Kalamaria). The use of Public Transport buses is also notable ( $6 \%$ compared to $1 \%$ in Kalamaria). Finally, a significant part of the students use motorbikes and motorcycles (13\%) compared to the respective $1 \%$ in Kalamaria. This fact imposes the need for an intensive effort by the authorities in order to educate these students on road safety. 


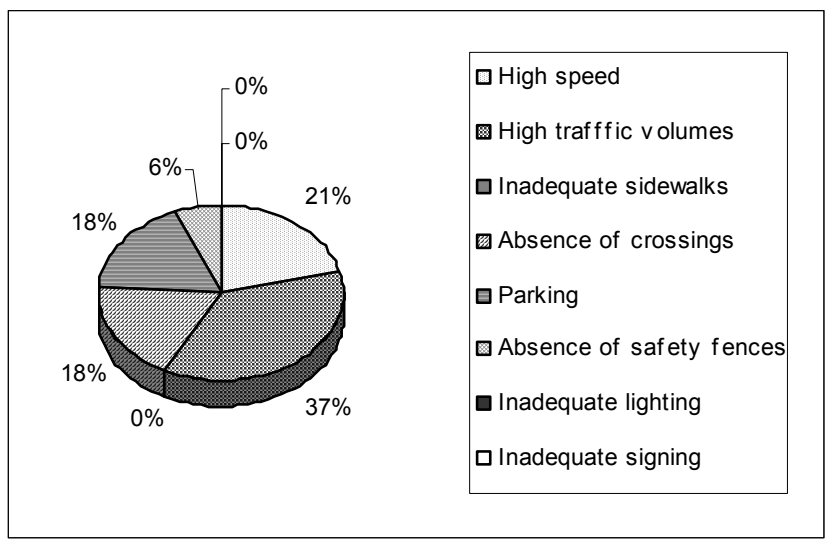

Figure 7: Reasons for the "unsafe" and very "unsafe" answers.

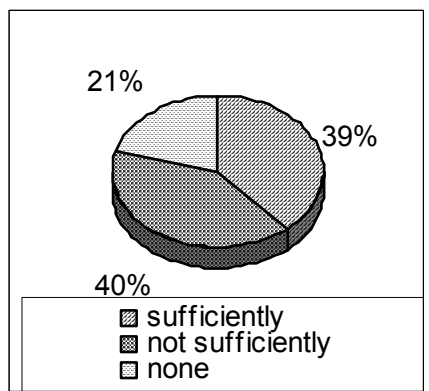

Figure 8: Level of HC knowledge Figure 9: Participation to traffic in Larissa.

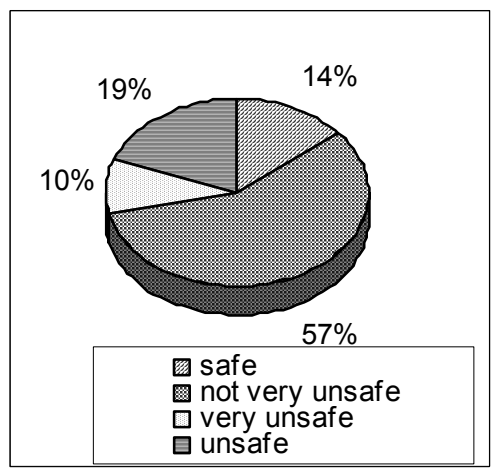

Participated

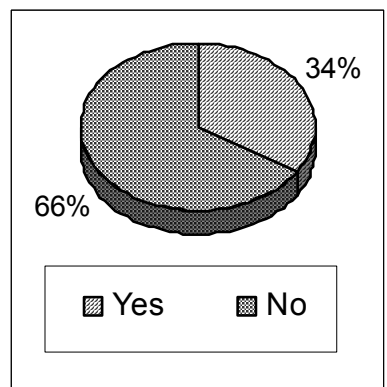
education events in Larissa.

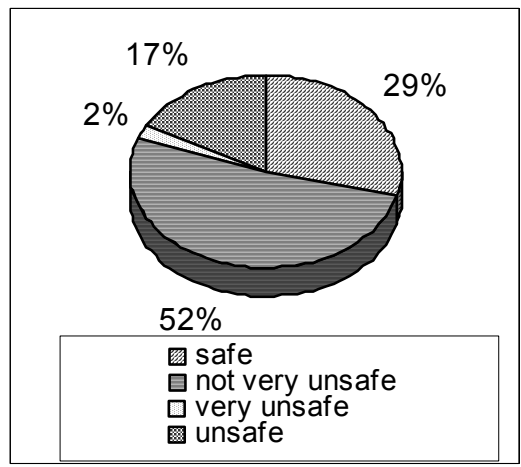

Not participated

Figure 10: Perception of traffic safety level by high school students in Larisa related to their participation to a traffic education event. 


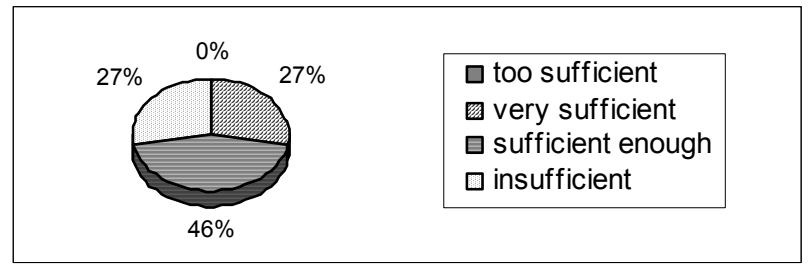

Figure 11: Opinions of the high school students in Larissa for the traffic calming measures in their school areas.

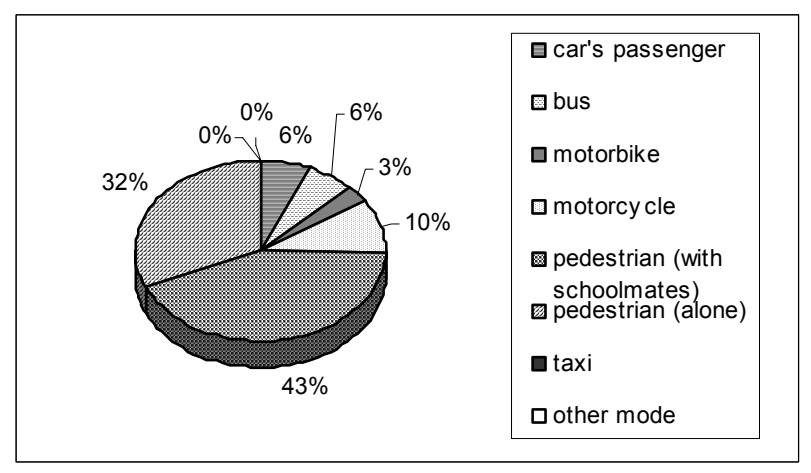

Figure 12: Transport mode used to and from school from in Larissa.

\section{Conclusions}

A notable percentage of $22-23 \%$ of students (age 12-14) feel unsafe or very unsafe on their trip to and from school. High speed of vehicles, high traffic volumes, inadequate sidewalks, absence of pedestrian crossings and limited visual field due to parking are the basic reasons. Almost 1/5 of the students are unfamiliar with the Highway Code while around $1 / 3$ of them participated in traffic education events. It is not clear how these events affect their perception of safety level. Traffic calming measures in the vicinity of schools are considered insufficient by $16-27 \%$ of the students. Finally the vast majority of students (75$94 \%$ ) prefer to walk to and from school.

\section{References}

[1] Darcin, M. \& Darcin, E.S. Relationship between quality of life and child traffic fatalities, Accident Analysis \& Prevention, in press, 2007.

[2] Timperio, A., Crawford, D., Telford, A. \& Salmon, J. Perception about the local neighborhood and walking and cycling among children, Preventive Medicine, 38, pp. 39-47, 2004. 
[3] Tranter, P. \& Whitelegg, J. Children's travel behaviour in Canberra: cardependent lifestyles in a low-density city, Journal of Transport Geography, 2, pp. 265-273, 1994.

[4] Rathinam, C., Nair, N., Gupta, A., Joshi, S. \& Bansal, S. Self-reported motorcycle riding behaviour among school children in India, Accident Analysis \& Prevention, 39, pp. 334-339, 2007.

[5] Poudel-Tandukar, K., Nakahara, S., Ichikawa, M., Poudel, K.C. \& Wakai, S. Relationship between mechanisms and activities at the time of pedestrian injury and activity among school adolescents in Kathmandu, Nepal, Accident Analysis \& Prevention, 38, pp. 1058-1063, 2006.

[6] Johansson, C. \& Leden, L. Short-term effects of countermeasures for improved safety and mobility at marked pedestrian crosswalks in Boras, Sweden, Accident Analysis \& Prevention, in press, 2006.

[7] Leden, L., Garder, P. \& Johansson, C. Safe pedestrian crossings for children and elderly, Accident Analysis \& Prevention, 38, pp. 289-294, 2006.

[8] Connelly, M.L., Conaglen, H.M., Parsonson, B. \& Isler, R.B. Child Pedestrians' crossing gap thresholds, Accident Analysis \& Prevention, 4, pp. 443-453, 1998.

[9] West, R., Sammons, P. \& West, A. Effects of a traffic club on road safety knowledge and self-reported behaviour of young children and their parents, Accident Analysis \& Prevention, 25, pp. 609-618, 1993.

[10] The Cochrane Injuries Group Driver Education Reviewers, Evidence based road safety: the Driving Standards Agency's schools programme, THE LANCET, 358, pp. 230-232, 2001.

[11] Cross, D., Stevenson, M., Hall, M., Burns, S., Laughlin, D., Officer, J. \& Howat, P. Child Pedestrian Injury Prevention Project: Student Results, Preventive Medicine, 30, pp. 179-187, 2000.

[12] Van Schagen, I. \& Rothengatter, T. Classroom Instructions versus Roadside Training in Traffic Safety Education, Journal of Applied Developmental Psychology, 18, pp. 283-292, 1997.

[13] Lam, L.T. Parental risk perceptions of childhood pedestrian road safety: A cross cultural comparison, Journal of Safety Research, 36, pp. 181-187, 2005.

[14] Collins, D.C.A. \& Kearns, R.A. Geographies of inequality: Child pedestrian injury and walking school buses in Auckland, New Zealand, Social Science \& Medicine, 60, pp. 61-69, 2005.

[15] Gregersen, N.P. \& Nolen, S. Children's road safety and the strategy of voluntary traffic safety clubs, Accident Analysis \& Prevention, 26, pp. 463-470, 1994.

[16] Themelis, G. \& Doumas, A. Investigation of road safety level in school areas, Diploma Thesis, Supervisor: Basbas, S., AUTh, 2003.

[17] Giatas, A. \& Pampouridis, A. Traffic calming measures for vulnerable road users in school areas, Diploma Thesis, Supervisor: Basbas, S., AUTh, 2006. 